\title{
Computer-Assisted Language Learning: A Study of EFL Teachers' Perceptions of University of Sindh, Jamshoro
}

\author{
Talha Memon ${ }^{1} \quad$ Syed Waqar Ali Shah ${ }^{2}$ Dr. Shumaila Aijaz Memon ${ }^{3}$ \\ 1.MS Scholar, Mehran University of Engineering \& Technology, Jamshoro \\ 2.Lecturer, Mehran University of Engineering \& Technology, Jamshoro \\ 3.Associate Professor, Mehran University of Engineering \& Technology, Jamshoro
}

\begin{abstract}
This study aims to investigate EFL teachers' perceptions on Computer Assisted Language Learning in English language classrooms. For the last 15 years, there has been great interest in researching teachers' perceptions, thinking and beliefs towards implementation of ICT in English language teaching classrooms. As teachers' perceptions shape and determine language teaching and learning practice. To investigate the problem, 47 in service teachers of Higher Secondary Schools were taken as participants, out of which there were 14 females and 33 males. A questionnaire was administered among the EFL teachers based on investigation of beliefs and perspectives of EFL teachers. Findings of the study suggest that use of online web chats and other connecting forums are practiced by EFL teachers to interact with the students. Furthermore, preparing lectures to use computers and getting help for material development is highly frequent.
\end{abstract}

Keywords: EFL Teachers' Perceptions, Computer Assisted Language Learning, implementation of ICT, English language classrooms

DOI: $10.7176 / \mathrm{JEP} / 11-30-04$

Publication date:October $31^{\text {st }} 2020$

\section{Introduction}

Interest in implementing technology into language classrooms has been very old which can be traced back through the use of different terms ranging from 'computer-assisted language learning (CALL)' to 'technology-enhanced learning' and to 'information and communication technology (ICT)' (Dudeney \& Hockly, 2012). Use of different terms shows that different attempts have been made to integrate technology into language classrooms for language learners. It seems that the idea is not a novel one. Since its start from late 1970s and early 1980s, teachers have been attempting to incorporate technology to assist learning, and the approach of integration has been under flux (Hubbard \& Levy, 2016). Luke and Britten (2007) predicted back a decade ago that use of technology would be inevitable and teachers would need technological assistance to enhance opportunities for language learners to fulfill their needs. Bax's (2003) categorization of the use of technology in language classrooms is helpful. Using technology for teaching purposes in its earliest phase is termed as 'restricted'. In this phase technology was restricted to limited feedback for the learner and often without any communicative value. The second stage is referred as 'open' referring to our current practices with the advancements in internet and related interactive and productive practices. The last stage will be 'integrative' in which the integration of technology will become stabilized as something normal and an integral part of language learning. Teachers' role for this upcoming role is very important to be realized in advance as preparation (Healey, 2016). Although many studies have been conducted regarding the use of CALL which contribute experiential learning, motivation, student achievement, and greater interaction opportunities. These studies suggest that there are financial barriers, lack of technology related resources, insufficient teachers' training and skills and teachers' conditioned mind-set in traditional teaching methods (Lee, 2000).

There has been awareness of challenges brought by software and hardware in deciding what would prove to be the best practice for their classrooms (As,1k, 2016). Successful use of technology does not mean using technology more frequently in and out of classrooms. It requires mastery over content, training, technical skills and environment for its use.

\subsection{Understanding Teachers' Cognition}

Since last 15 years, there has been great interest in studying language teachers' perceptions and beliefs- knowing what they think, believe in relation to their classroom practices. (Borg, 2006, p. 1). Different terms have been used by Borg (1998) to capture L2 teachers' beliefs like: 'personal pedagogical system' 'teachers' theories' and 'teacher cognition'. Gibbon' noted that five terms have been in use interchangeably in research to refer teachers' cognition which includes: teacher beliefs, teacher cognitions, teacher perceptions, pedagogical beliefs and teacher thinking. These days, it is teachers' cognition that is commonly used as an umbrella terms for above mentioned terms. Moreover, to understand the complex nature of teachers' mental lives, a theory of teacher cognition has emerged (Borg, 2006). This shows teachers' cognition of their classroom practices is a guiding force. A number of conducted in the field suggest that there exist 'symbiotic relationships' between teachers' cognition and their 
classroom practices (Foss \& Kleinsasser 1996: 441). Review of these studies demonstrate that there are factors like teachers' personal approaches, personal beliefs and pedagogical priorities shape and direct their language practices in classrooms.

\section{Literature review}

\subsection{Teachers' opinions about language teaching and ICT}

The importance of opinions led Ottenbreit-Leftwich, Braak, Tondeur, Ertmer (2017) to analyse literature to recognize the connection among teachers' views on teaching and usage of technology in learning. 14 particular qualitative case revisions were studied by engaging meta-aggregate method for analysis of the data. The results testified a bi-directional connection among teaching opinions of educators and technology. Olofosson and Englund, and Price's (2017) study attempts to investigate the conceptions of learning and methods of university level teachers for ten years. The results showed that the teachers were primarily more disposed to teachers-centered concepts about teaching with technology; though, later the similar teachers proved far better and faster adaptableness to transformation than the skilled teachers. Equally, additional skillful teachers presented insignificant transformation in their conceptions.

The attitudes reflect inner views that effect our action and display features like morality, kindness and obligation (Schunk, 2012). However previous attitudes effect equipment receiving, with steady growth in equipment dispersion, users' attitudes unceasingly form for additional reception and usage of ICT (Dutschke, Bogel, Oltra, Upham, Wiemanm, Sala, Lores, 2018). Player-Koro, (2012) in his study examined issues which effect educators' usage of ICT in learning. The study formulated a way to discover teacher associated contributing features of ICT usage. The results showed that encouraging attitude and self- effectiveness of educators influenced ICT usage. Though, educators' overall encouraging attitudes failed to produce desired outcomes. Furthermore, educators' self-assurance empowered them to profit their specialized skills, and enabled learner's learning. Likewise, Zhou, Huang and Teo (2017), in the University of China studied the Instructors of English by discovering features that inclined educators who are trained with technological equipment. The results showed English language instructors' encouraging attitudes to the usage of equipment in education. Furthermore, communal effects, reassuring situations, and effectiveness of machinery were chief features including the welcome of technology. The study recommended enhancement in the Education of University by educator skilled progress, and educators' teaching methods of assimilating technology in learning.

Efforts have been made to examine the connection between educators' educational opinions that their views about ICT assimilation or/and ICT centered performance based on an assumption that varying standards and opinions educators have on teaching can lead to different methods of assimilating ICT in the classrooms (Ottenbreit Leftwich, 2010). Apparently, traditional educators incline to manipulate ICT as a supplementary instrument to support learning resources, send projects and search material on the internet (Ertmer, 2012). Though, ICT is measured as a cognitive instrument that inspires learner's to integrate their critical-thinking, collaboration, communication, and problem-solving skills into their learning to solve authentic problems (Ertmer, 2015). Whereas other studies manifested the effect of pedagogical perceptions on their ICT integration (Prestridge, 2012). On the contrary, there are studies conducted which revealed differences between these perceptions and the integration of ICT in their teaching practices (Chen, 2008; Judson, 2006). Ertmer et al. (2015) found the reasons causing such inconsistencies. These include: perceptons as an ambiguous element to measure, weight these perceptions hold for an individual teacher, and varying cultural contexts.

\subsection{Technology-mediated Instruction in Pakistan}

Rashid (2018) conducted a study in Pakistan to explore the technology use of the learners of Pakistan in and out of the classrooms. The study revealed that the learners are well conscious of technical usages.

It was revealed that $(96 \%)$ of the learners are equipped with the smartphones while $(85 \%)$ of the learners practice the desktops and CPUs for education associated problems. The majority of the learners get support from the smartphones though they are in the campus. Exercise of carrying CPUs or using the campus provided processors was not widespread. In a study conducted by Ahmed showed that the usage of the smartphones has improved from the 30 to 50 percent within the period of 2 years (2017). Ahmed et al establishes that the emphasis on assuming new approaches was a deserted part in the universities of Pakistan. The best trained technique in the classrooms was lecture method which make the students inactive receiver therefore simple follower. The further most mutual skillful usage of technological apparatuses was WhatsApp and the Facebook which is applied for the non-educational intentions mostly.

Baloch (2014) well defined that the outcomes can be widespread that established and emerging context where accommodations and communication linked to ICT are too low. In $142^{\text {nd }}$ places Pakistan is still a developing country in ICT index 166 economies also. The research on usage of technology by students in academic or nonacademic purpose is ignored still in Pakistani context. (Arif \& Kanwal, 2016, Hussain Bhutto, Rai, Hussain \& Zaheer, 2016,). They have generalized that a few researches have been conducted on in the field of technology. 
The majority of Pakistani researchers had aim to define the networking area by teachers and students in educational and non- educational area. And the usage of internet is by tertiary students. (Bashir, Mahmood \& Shafique, 2016), they stated that the usage of digital practices is going beyond access, experiences and skills in use of ICT. (Abushanab \&Al-Jamal, 2015) they are being influenced by disabilities, incomes and education.

United Nation e- Government knowledge and database (2017) reported that In Pakistan, English is the second official language but first language is few only $10 \%$ of that, $10 \%$ the majority are 20 to 24 years old in different institutions in Pakistan. Those students come with two important education sectors. One is Urdu medium where the Urdu language is promoted for instruction, and second one is English medium schools where the language of English is promoted for instruction. Higher education (2014), found that in Pakistan the two types of schools are founded which are promoted. One is private schools and other one is government schools. The most of the public schools are Urdu medium where rural area's students get education. In private schools the education is given to upper and middle class families. In private schools teachers are qualified and more trained high quality classrooms and best material is given for teaching to students as compare to public schools. (Dogar, Butt\& Qaisar, 2015) described that English medium schools have well educations system, such as facilities of technology, digital tools, computer project and best digital libraries as compare to Urdu medium schools (Shah \& Ried 2016 and Siddiqui \&Gorard, 2017).

Shabir et al (2014) proposed that technology such as, digital facilities are positive influenced on English medium schools' skills. Salam et al (2017) explained that the Urdu medium schools students' use of digital tools on personal activities such as at home. Many digital devices are growing such as popularity of smart phones in Pakistan recent years. The news was published in nation in (2016), searched that the use of Smartphone is counted in Pakistan 40 million by the end 2016. Lee, Park\& Hwang (2015; Mascheroni \& Olafsson (2015) claimed that many researchers researched that the effect of mobile technologies on the digital device in developed countries. Puspitasari \& Ishii (2016) explained that mobile technology helps with leapfrogging the digital devices in developing countries (Chen \& Denoyelles, 2013). They have explained that the benefit of mobile devices in learning and teaching have also documented by many investigators. Moreover, in Pakistan yet no one research on exploring the usage of smart phones in English language. It is also informed that how students are using a mobile phones for learning English language. Rashid et al, defined that technology increased English language practices in Pakistan 67 has been collected on students' earlier digital and mobile assistant language learning(MALL) practices, as well as demographic factors. That would be impact on their digital and MALL practices to create what is already has been done. And to know insights exploit educational outcomes by integrating students digital devices.

\subsection{Teachers' beliefs about use of CALL resources in Pakistan}

Chandio (2018) narrates that the massive adaption of ICT in socio-economic landscape is very necessary in educational sector. ICT has certain educational priorities in line with technological trends because it has proved a productive factor in the innovation of higher education. Various studies have conducted on this particular topic. The literature portraits two major volumes (Vol. 6 No 2 December 2019, 31) Zamir and Thomas' research focuses on two different factors. The one which is focused on the effect of internal factors whereas the other is identified the external factors. Chandio et al. (2018) attempted to study on the acceptance and implementation of ICT in public sector universities of Pakistan. They revealed that the ICT implementation was slow due to external factors, such as, conducive environment and non- availability of equipment. However, ICT acceptance and use largely depended on applicability and relevance to the course field of teaching.

Questions of the study

For a better understanding of the problem, the present study has attempted to address the following questions:

1. What is EFL teacher cognition about use of technology in English language instruction at Secondary schools in Pakistan?

2. How do EFL teachers perceive their practices and roles in relation to in their technology-mediated EFL instruction at secondary schools?

\section{Research Methodology}

Based on the research objectives and questions of the study, the present researcher has used quantitative approach in order to explain the results in an effective manner collected through different research instruments. Triangulation technique was employed in this study. Patton (1990) maintains that triangulation helps to produce better results in quality and scope.

\subsection{Sampling \& Participants of the Study}

The participants were in-service teachers from seven secondary schools in Pakistan. The number of participants for the present study included 47, out of which there were 14 females and 33 males. All the participants varied in their qualification ranging from bachelors to masters in English. 


\subsection{Data Collection Instrument}

The questionnaire used in the present study was adopted from Suwannasom (2010), and further adapted keeping the contextual factors in view. The questionnaire contains two sections. The first section is related participants' personal information, beliefs and perception about IT in EFL Instruction. The second section of the questionnaire investigates the participants' beliefs and experiences in integrating IT in EFL classes.

\section{Data Analysis}

\subsection{Technology uses that describe the most frequent EFL instructional behaviors of Teachers}

The study finds that majority of the teachers use computers for preparing their lectures for the classrooms and prepares their teaching materials for the students. Moreover, they use and download materials online to facilitate their teaching in EFL contexts. This makes $38 \%$ of the participants where as $7 \%$ of the participants agree that they use chatrooms with their students to share materials with them. Only two participants out of 57 did not create online blogs or websites, nor did they engage students in online testing and assessment. The findings match with the previous studies by Murray (2005) who states that that the goal of language learning in digital age is to train the learners to communicate with people around the world through digital tools such computers and internet links. Keeping this in mind, the ultimate goal of teaching activity is to provide meaning language practices and experiences to the learners required in electronic communication (Chapelle, 2001). In the present study, the participants are also seen to be engaged in online communication with the teachers and the learners as well. Ten participants in the present study use Moodle and other web sources to organize interaction in the language classrooms.

\subsection{The extent of the use of IT in English language instruction supported or encouraged at your institution} The number of those participants who think the technology is somewhat supported is comparatively higher than those who responded on complete support or no support at all. It forms $47 \%$ of the total population in the present study. It shows that technology is somewhat encouraged and supported at the participants' institute. Only 4 participants strongly agreed that technology is highly encouraged in EFL classrooms. On the other hand, 13 participants disagreed that the technology is either supported or encouraged at their institutes. The findings support the study conducted by Felix (2001) who thinks that students do not get opportunities to get feedback on their language tasks.

\subsection{Beliefs about use of IT in Pakistani EFL classrooms}

The highest mean value is revealed in B10 i.e. 3.49 which shows that the EFL learners read online journals and websites where the native speakers contribute in writing various essays and articles. Native speakers' genre of writing is thought to be an ideal model of English by the students. This is in conformity with the study by Kern and Warschauer (2000) who point out the fact that language learners with access to the internet can interact with the native speakers around the world to improve their linguistic competence. The native speakers bring in the real use language to the nonnative speakers who can make the most of it. The learners have an opportunity anywhere be it home, workplace, or the school. The second highest mean value in the present study is 3.39 which tell that the emails and chatrooms are normally used to promote knowledge and the students are encouraged to construct or share knowledge through online chatrooms. Kem (1996) seems to support the findings of the present study who states that e-mails, web chats and other connecting links creates the room for teachers to use communicative language teaching in the classrooms. Moreover, the students feel less anxious in the classrooms as they have no fear of participating in language activities. They feel more motivated to learn a foreign language. The findings of the present study are also support by Davis (2006) who states that the learners create meaningful conversations and receive feedback through web 2.0. These several opportunities facilitate learning and teaching equally.

The majority of the participants remained neutral on student's word processing their assignments to correct their spellings and structure. Moreover, somehow equal number of participants agreed and disagreed that students use CD-ROMs and other web-based sources to learn pronunciation and solve grammatical exercises.

\subsection{Integration of Web based Activities in EFL Classroom}

In this section, the findings of the integration of web based activities in EFL classrooms are discussion on the basis of the previous studies. The study finds that EFL teachers sometimes keep an e-journal or web based log about their teaching. Smith (1997) states that the researchers and teachers around the world have recently adopted several web sources including Web 2.0 and Lesson Management System (LMS) in EFL classrooms. Web 2.0 which includes the recent innovative technological tools such as wikis, postcards, and social networks is of much help for both the professionals and language learners. The present study shows that in Pakistani context, the teachers do not usually keep the record in e-journal or other web sources. The study also finds that those EFL teachers rarely engage their students in web-based discussion in EFL classrooms. 


\subsection{Summary of the Results}

The EFL teachers use online web chats and other connecting forums to interact with the students and use computers to prepare their lectures and materials for language classes. Less than $50 \%$ of the participants agreed that technology is supported and encouraged at their institutes. That shows that it is not highly encouraged in Pakistani context. In addition, a good number of the participants agreed that most of the students read online journals and manuals where the native speaker seems to have contributed. Native variety is considered the ideal modal for language and access to it is only possible through technology integration in EFL classrooms. However, a few challenges arise for teachers in Pakistani context. They do not engage the students in online testing and evaluation. And they do not have online websites and blogs that could facilitate teaching in EFL classrooms.

\section{Conclusion}

This investigation was designed with a view to contributing to the existing knowledge of teacher cognition about IT integration in Pakistani EFL context. The Pakistani ministry of Higher Education (2011) not only set objectives for enhancing English language skills, but also laid focus on integration of ICT in language education so as to go in line with international teaching norms. The present study shows that there is a much improvement in Educational set up in Pakistani context and the targets set by Pakistani Ministry of Higher Education somehow seem to be realized. However, there are a few challenges which hinder the integration of IT in EFL classrooms as the study found that less than 50\% participants agreed on the fact the institutes allow IT integration in EFL classrooms. They do not encourage or support online learning. Moreover, the system is not yet developed to assess students' proficiency through web-based sources.

\section{References}

Ahmed, K. (2017). Pakistan emerges as top market for smartphones. Daily Times.

Baloch, F. (2014, November). ICT ranking: Pakistan among least connected nations, stands at 142nd place. The Express Tribune. Retrieved from https://ribune.com.pk/story/799668/ict-ranking-pakistan-among-leastconnected-nations-stands-at-142nd-place/

Bax, S. (2003). CALL-Past, present and future. System, 31(1), 13-28. doi:10.1016/S0346-251X(02)00071-4

Borg, G. (1998). Borg's perceived exertion and pain scales. Human kinetics.

Braun, V., \& Clarke, V. (2006). Using thematic analysis in psychology. Qualitative research in psychology, 3(2), 77-101.

Chomsky, N. (1960). Language \& Mind. Cambrdige University Press

Cohen, L. and Manion, L. (2008) Research Methods in Education, New York City, NY: Routledge Falmer. Cohen, L., Manion, L. and Morrison, K. (2000), in Research Methods in Education, New York City, NY: Routledge Falmer.

Dogar, A. H., Butt, T. M., Butt, I. H., \& Qaisar, S. (2015). Revisiting Pakistan's education system: Addressing the key-flaw. The Dialogue, 10(4), 390-394.

Dudeney, G., \& Hockly, N. (2012). ICT in ELT: How did we get here and where are we going? ELT Journal, 66(4), 533-542. doi:10.1093/elt/ccs050

Erstmer, P. A (2005). Teacher Pedagogical Beliefs: The final frontier in our quest for technological integration? Educational Technology Research \& Development. 53(4). 25-39

Harris, C. L. (2009). Language \& Cognition. Boston University, USA

Healey, D. (2016). Language learning and technology: Past, present and future. In Farr

F., and Murray L. (Eds.), The Routledge Handbook of Language Learning and Technology (pp. 9-23.). New York, NY: Routledge

Livingstone, S., Mascheroni, G., Olafsson, K., \& Haddon, L. (2015). Children's online risks and opportunities: Comparative findings of EU Kids Online and Net Children Go mobile. November 2014.

Luke, C. L., \& Britten, J. S. (2007). The expanding role of technology in foreign language teacher education programs. CALICO Journal, 24(2), 253-267. doi:10.1558/cj.v24i2.253-268

Puspitasari, L., \& Ishii, K. (2016). Digital divides and mobile Internet in Indonesia: Impact of smartphones. Telematics and Informatics, 33(2), 472-483.

Rachid, S., Cunningham, U., Watson, K., \& Howard, J. (2018). Revisiting the digital divide (s): Technologyenhanced English language practices at a university in Pakistan. 